\title{
PENUNDAAN KEHADIRAN ANAK AKIBAT PERKAWINAN USIA MUDA DITINJAU MENURUT HUKUM ISLAM (STUDI PADA DESA JALING KEC. AWANGPONE KAB. BONE)
}

\author{
Wiwin Pranata \\ Institut Agama Islam Negeri (IAIN) Bone \\ Email : wiwinpranta@gmail.com \\ Abdul Rahim \\ Institut Agama Islam Negeri (IAIN) Bone \\ Email : rahimilmi72@gmail..com
}

\begin{tabular}{|c|c|}
\hline Keywords : & ABSTRACT \\
\hline $\begin{array}{l}\text { early marriage and islamic } \\
\text { law's perspective }\end{array}$ & $\begin{array}{l}\text { The aim of the study is to identify whether early marriage contributes to } \\
\text { delaying childbirth and to identify Islamic perspective in relation delaying } \\
\text { childbirth. As for the advantages of the research, theoretically, the results of } \\
\text { this study are expected to contribute positively to all components of the } \\
\text { student, so the idea of delaying childbirth due to early marriage is able to be } \\
\text { understood. Practically, this research will be one of the reference materials for } \\
\text { further study in wider scope. The results of the study indicated that some } \\
\text { people perform delaying childbirth due to early marriage through their } \\
\text { participation in Family Planning Program (KB) by injections. The } \\
\text { incentivizing factors of their participation within the program are age and } \\
\text { educational factor, in which the Islamic law consider this permissible only if } \\
\text { there is an agreement between both husband and wife, it is temporary, not } \\
\text { harmful and beneficial }\end{array}$ \\
\hline
\end{tabular}




\section{PENDAHULUAN}

Dalam Islam, perkawinan merupakan suatu cara manusiawi yang terpuji untuk menyalurkan nafsu seks bagi seorang agar tidak menimbulkan kerusakan dalam masyarakat dan juga mengandung suatu sarana untuk meraih kesempurnaan rohani agar suami istri hidup tentram, cinta mencintai dan kasih mengasihi yang dalam Al-Qur'an dikenal dengan sebutan mawaddah wa rabmah.

Kaitannya dengan pengertian nikah atau perkawinan menurut pandangan imam mazhab, golongan Malikiyah mendefinisikan nikah sebagai berikut:

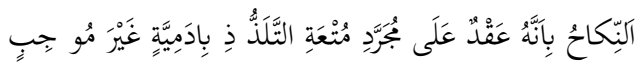

$$
\text { قِيْمَتَهَا بِبَيْنَة }
$$

Artinya:

"...Nikah adalah akad yang mengandung ketentuan hukum semata-mata untuk membolehkan watha bersenang-senang dan menikmati apa yang ada pada diri seorang wanita boleh nikah dengannya."1

Dari sudut pandangan Islam, perkawinan adalah satu-satunya cara yang berguna untuk menjaga kebahagiaan ummat dari kerusakan dan kemerosotan akhlak. Selain dari itu perkawinan juga dapat menjaga keselamatan individu dari pengaruh kerusakan masyarakat karena kecenderungan nafsu kepada jenis kelamin yang berbeda dapat dipenuhi melalui perkawinan yang sah dan hubungan yang halal. Dalam Kompilasi Hukum Islam dikemukakan bahwa perkawinan menurut islam adalah pernikahan, yaitu aqad yang

${ }^{1}$ Abdurrahman al-Jaziri, Kitab Ala alMahzahib al-Arba'ah, Juz IV (Mesir: Dar al-Fikr, 1976) h. 2

2Zainal Abidin Abu Bakar, Kumpulan Peraturan Perundang-undangan dalam Lingkungan Peradilan Agama, (Cet. II; Jakarta: Yayasan al-Hikmah, 1993), h. 307 sangat kuat atau mitsaqan ghalidzan untuk mentaati perintah Allah. ${ }^{2}$

Perkawinan usia muda adalah perkawinan yang dilakukan oleh sepasang laki-laki dan perempuan remaja. Menurut UU Perkawinan No. 1 Tahun 1974 pasal 7 "Perkawinan banya dizinkan jika pibak pria sudah mencapai umur 19 tabun dan pibak perempuan sudah mencapai 16 tabun". Namun pemerintahmempunyai kebijakan upaya penyelenggaraan keluarga berencana. Banyaknya resiko kehamilan yang terjadi jika usia perkawinan di bawah umur 19 tahun. $^{3}$

Terkait dengan batasan umur perkawinan, Bimo Walgito, 1984, berpendapat bahwa umur seseorang mempunyai peranan dalam perkawinan. Umur seseorang berhubungan dengan aspek fisiologis dan psikologis. Dari aspek fisiologis batasan perkawinan pada umur 16 dan 19 tahun sebagaimana dalam undang-undang perkawinan No. 1 tahun 1974 dianggap sudah cukup masak, karena pada usia tersebut pasangan nikah sudah dapat membuahkan keturunan, karena dari segi biologis alat-alat reproduksi telah berfungsi. tetapi dari aspek psikologis pada umur 16 tahun maupun 19 tahun pada umumnya masih digolongkan pada umur remaja atau adolensi belum termasuk kategori dewasa. ${ }^{4}$

Bagi pasangan suami istri yang belum siap melahirkan keturunan biasanya melakukan Keluarga Berencana (KB) sebagai daya upaya manusia untuk mengatur secara sengaja kehamilan dalam keluarga, sesuai dengan perencanaan keluarga sehat. Penundaan kehamilan pada usia di bawah 21 tahun ini biasanya dengan dilakukan menggunakan alat kontrasepsi

\footnotetext{
${ }^{3}$ Intan Kumalasari, Iwan Andhyantoro, Kesehatan Reproduksi Untuk Mahasiswa Kebidanan Dan Keperawatam, (Cet. II; Jakarta: Salemba Medika, 2013), h. 119
}

${ }^{4}$ Bimo Walgito, Bimbingan dan Konseling Perkawinan (Yogyakarta : Yayasan Penerbit Fakultas Psikologi UGM, 1984), h. 29 
Website: https://journal.stiba.ac.id

ISSN : 2685-7537 (online) 2338-5251 (Printed)

berupa suntikan, pil, kondom dan sebagainya.

Dengan dilaksanakan keluarga program (KB) merupakan salah satu upaya yang dilaksanakan pemerintah dalam mengatasi dampak yang ditimbulkan dari perkawinan usia muda yang dapat menganggu kesehatan dari ibu dan anak yang dilahirkan.Dahulu pernikahan usia muda dianggap lumrah. Tahun berganti, makin banyak yang menentang pernikahan usia muda namun fenomena ini kembali lagi. Jika dahulu orang tua ingin agar anaknya menikah muda fenomena perkawinan di usia muda masih sangat tinggi. Hal tersebut terlihat dari maraknya perkawinan usia muda pada kalangan remaja, yang kini tidak hanya terjadi di pedesaan tetapi juga kota-kota besar di Indonesia. Fenomena perkawinan usia muda ini tampaknya berbagai alasan, maka kini tidak sedikit remaja sendiri, bukan hanya remaja pedesaan tetapi juga remaja di kota besar, yang ingin menundah perkawinan.

Perkawinan di usia muda hanyalah sepenggal realitas sosial yang dihadapi masyarakat saat ini. Pada kalangan remaja, pernikahan di usia muda ini dianggap sebagai jalan keluar untuk menghindari seks bebas. Ada juga yang melakukannya karena terpaksa dan karena hamil di luar nikah.

Karena pada zaman sekarang banyak sekali perkawinan usia muda yang terjadi disekitar kita baik itu teman, tetangga mau pun keluarga kita sendiri, dan rata-rata usia mereka berkisaran antara 1617 tahun bahkan ada dibawa usia tersebut, dimana mereka masih duduk di bangku sekolah (SMA),dan rata-rata alasan mereka menikah muda, tidak lain karena terpaksa mengikuti keinginan orang tua mereka (dijodohkan).

Dan tidak sedikit dari mereka setelah menikah ingin menunda kehadiran anak terlebih dahulu, dan motif mereka menunda kehamilan sering dilakukan oleh pasangan muda atau pasangan yang masih disibukkan dengan karirnya. Umur mereka masih sangat muda, Belum siap memiliki anak, belum mapan, masih mengejar karir, belum sukses, sering menjadi alasan pasangan suami istri menunda kehamilannya terlebih dahuludan banyak lagi motif-motif ataupun faktor-faktor mereka sehingga menunda kehadiran anak terlebih dahulu akibat

Berdasarkan latar belakang di atas, maka saya selaku calon peneliti mengadakan penelitian sebagai sumbangsih pemikiran dalam meneliti penelitian dengan judul : "penundaan kehadiran anak akibat Perkawinan Usia Muda ditinjau pada bukum islam (studi pada desa jaling,kab. Bone) ".

Merujuk pada pokok masalah di atas, peneliti menentukan sub masalah yang dianggap perlu untuk dijadikan pembahasan yaitu Apa ada yang terjadi penundaan kehadiran anak akibat perkawinan usia muda di Desa Jaling Kec.Awangpone Kab.Bone dan Apa pandangan hukum islam terhadap penundaan kehadiran anak dalam perkawinan usia muda di Desa Jaling Kec.Awangpone Kab.Bone.

\section{PEMBAHASAN}

\section{Penundaan Kehadiran Anak Akibat Perkawinan Usia Muda di Desa Jaling Kec. Awangpone Kab. Bone.}

Dari beberapa macam alat kontrasepsi yang diprogramkan itu sebagian besar sasaran pemakaiannya adalah wanita, yaitu: pil, suntikan, susuk KB, AKDR, dan kadang-kadang tubeksomi, sedangkan laki-laki hanya kondom dan vasektomi.

Dalam wawancara penulis dengan beberapa bidan di desa jaling, kec. Awangpone kab. Bone berpendapat mengenai alat-alat $\mathrm{KB}$ yang mereka pakai dan alasan mereka menunda kehamilan serta efek/dampak yang ditimbulkan akibat alat $\mathrm{KB}$ tersebut.

Bidan Dahliah mengatakan: 
Website: https://journal.stiba.ac.id

ISSN : 2685-7537 (online) 2338-5251 (Printed)

"Banyak sekali yang melakukan penundaan kehadiran anak atau penundaan kehamilan, baik itu kaum muda yang baru menikah maupun mereka yang sudah dikarunia anak dan alasan atau pun motif mereka beragam sehingga melakukan penundaan.Tapi adik kan memfokus ke kaum mudanya adapun alasan ataupun motif nya Antara lain:

1. Faktor umur sehingga mereka menunda kehamilan terlebih dulu, karena meraka tahu resikonya sangat tinggi ketika hamil muda.

2. Faktor pendidikan (karir). ${ }^{5}$

"Sedangkan menurut bidan Suriani dan bidan Rahmah senada dengan bidan Dahliah ada beberapa pasangan yang baru menikah yang melakukan penundaan kehamilan, dan ke banyakan mereka menunda kehadiran anak karena faktor tertentu antara lain:

1. Faktor umur mereka yang masih muda karena mereka tahu resikonya sangat tinggi ketika hamil muda.

2. Faktor pendidikan karena kebanyak mereka menikah muda sehingga menunda kehamilan terlebih dulu. ${ }^{6}$

Dari penjelasan diatas dapat dipahami yang mengakibatkan mereka melakukan penundaan kehadiran anak atau penundaan kehamilan karena faktor usia mereka yang masih muda dan faktor pendidikan sehingga mereka melakukan penundaan terlebih dahulu.

Bidan dahliah mengatakan:

Adapunalat KB yang mereka gunakan yaitu kebanyakan suntikan, suntikan 1 bulan dan ada juga yang menggunakan suntikan 3 bulan tapi suntikan 3 bulan

${ }^{5}$ Dahliah, Bidan Desa Jaling. “ Wawancara", Jaling, 04 Oktober 2016.

${ }^{6}$ Suriani Dan Rahmah, bidan Jaling." Wawancara", Jaling, 04 oktober 2016.

${ }^{7}$ Dahliah, Bidan Desa Jaling. "Wawancara", Jaling, 04 Oktober 2016. kebanyakan dipakai yang sudah mempunyai anak, sedangkan suntikan 1 bulan kebanyakan dipakai oleh mereka yang baru menikah. ${ }^{7}$

Begitupun bidan Suriani Dan Rahmah mengatakan:

Ada pun cara mereka menunda kehamilan dengan mengunakan suntikan KB 1 bulan. ${ }^{8}$

Dari penjelasan diatas dapat disimpulkan bawah bentuk penundaan kehadiran anak atau pun penundaan kehamilan yang mereka gunakan yaitu dengan mengikuti keluarga berencana yang berupa alat suntik KB.

Penulis telah melakukan wawancara terhadap beberapa masyarakat yang melakukan perkawinan usia muda dan yang melakukan penundaan kehamilan di Desa Jaling Kec. Awangpone Kab. Bone, antara lain:

1. Anatang 23 Tahun

"saya baru saja menikah dan usia saya 23 tahun. Adapun alasan saya menunda kehamilan karena pada saat itu saya masih kuliah dan menunggu sampai selesai kuliah. Dalam penundaan kehamilan; cara yang ditempuh dengan pemakaian suntikan 1 bulan $(\mathrm{KB})$, respon positif dari suami saya dengan meenrimanya karena keadaan saya yang pada saat ini karena masih kuliah."9

2. Nurhalisah 18 Tahun

"Pada usia 17 tahun, saya dijodohkan orang tua dan saat itu saya masih bersekolah di SMA kelas 3 dan menunggu hingga lulus dari SMA. Itulah

8Suriani Dan Rahmah, bidan Jaling. "Wawancara", Jaling, 04 oktober 2016.

${ }^{9}$ Anatang, Yang Melakukan Perkawinan Usia Muda dan Penundan Kehadiran Anak. “Wawancara”, Jaling, 04 Oktober 2016. 
Website: https://journal.stiba.ac.id

ISSN : 2685-7537 (online) 2338-5251 (Printed)

alasan saya menunda kehamilan. Saya mengunakan KB berupa suntikan 1 bulan, respon suami saya terima-terima saja dan mengerti." 10

3. Lydia 16 Tahun

"Saya dijodohkan orang tua saat saya berumur 15 tahun. Dikarenakan usia saya masih sangat muda dan juga saya sementara menempuh pendidikan di SMP. Olehnya itu, saya berinisiatif untuk menunda kehamilan sampai menamatkan pendidikan SMP karena saat itu saya tidak berencana untuk melanjutkan pendidikan sampai ke tahap SMA. Dalam menunda kehamilan, saya ber-KB dengan menggunakan suntikan 1 bulan. Adapun respon dari suami saya_setuju-setuju saja dan mengerti dengan keadaan saya saat itu."11

4. Siti Aisyah 18 Tahun

"di umur 17 tahun, saya dijodohkan orang tua. Saat itu saya masih sekolah di SMA kelas 3. Jadi,untuk sementara waktu saya ingin menunda kehamilan sampai saya menamamatkan SMA. Saya mengunakan KB berupa suntikan 1 bulan, respon suami saya terima-terima saja dan mengerti dengan keadaan saya pada saat itu."'12

Dari beberapa wawancara yang penulis lakukan dengan narasumber yang telah disebutkan sebelumnya, membuktikan bahwa perkawinan usia dini (usia muda) merupakan hasil dari perjodohan orang tua kepada anaknya. Kemudian, dari adanya perkawinan usia muda ini lahirlah inisiatif dari pelaku

${ }^{10}$ Nurhalisah, Yang Melakukan Perkawinan Usia Muda dan Penundan Kehadiran Anak. "Wawancara”, Jaling, 04 Oktober 2016.

${ }^{11}$ Lydia, Yang Melakukan Perkawinan Usia Muda dan Penundan Kehadiran Anak. "Wawancara", Jaling, 04 Oktober 2016. perkawinan dini untuk menunda kehamilan dini. Adapun usaha-usaha penundaan kehadiran anak berdasarkan pendapat dari para narasumber dapat disimpulkan bahwa alasan ataupun motif mereka menunda kehamilan karena usia mereka yang masih sangat belia (muda), belum selsesai nya pendidikan mereka dan bentuk penundaan kehamilan yang mereka lakukan dengan ber-KB dengan menggunakan suntikan.

Pandangan Hukum Islam Terhadap Penundaan Kehadiran anak Akibat Perkawinan Usia muda

Thariq At-Thawari dalam bukunya yang berjudul "KB Cara Islam" menjelaskan bahwa pada zaman Rasulullah saw., tidak ada seruan luas untuk ber-KB atau membatasi keturunan, atau mencegah kehamilan di tengah-tengah kaum muslimin. Tidak ada upaya dan usaha yang serius untuk menjadikan al-azl sebagai amalan yang meluas dan tindakan yang populer di tengah-tengah masyarakat.

Sebagian sahabat Rasulullah saw., yang melakukannya pun tidak lebih hanya pada kondisi darurat, dan ketika hal itu diperlakukan oleh keadaan pribadi mereka. Di samping itu, pertumbuhan sang anak pada masa menyusui juga teracam bila sang ibu hamil lagi. Dalam kondisi-kondisi seperti di atas, bila seseorang menggunakan salah satu cara atau alat untuk mencegah kehamilan setelah mendapat petunjuk dari dokter yang terpercaya, maka seseorang itu dibolehkan untuk melakukan hal tersebut.

Metode apapun yang digunakan untuk mencegah kehamilan boleh digunakan, asal disepakati oleh pasangan suami istri, dan tidak membahayakan tubuh dan nyawa mereka, serta tidak bertentangan serta bertolak belakang dengan Islam dan hukum-hukum. ${ }^{13}$

${ }^{12}$ Siti Aisyah, Yang Melakukan Perkawinan Usia Muda dan Penundan Kehadiran Anak. "Wawancara", Jaling, 04 Oktober 2016.

${ }^{13}$ Thariq At-thawari, KB Cara Islam (Cet I; Solo: Maktabah Shaidul Fawa'id alIslamiyyah, 2007), h. 97.

Wiwin P., Abdul R. Penundaan Kehadiran Anak... 
Website: https://journal.stiba.ac.id

ISSN : 2685-7537 (online) 2338-5251 (Printed)

Perihal dalam mengatur waktu kelahiran yang bersifat sementara dengan tujuan menjarangkan jarak kehamilan, atau menghentikannya untuk sementara waktu, jika secara syar'i ada tuntutan untuk hal tersebut berdasarkan perkiraan pasangan suami isteri dan musyawarah serta kesepakatan di antara mereka, maka dengan syarat bahwa hal tersebut tidak menimbulkan bahaya dan dengan cara yang disyariatkan serta bukan bertujuan menggugurkan kandungan yang ada."14

Pada zaman rasulullah saw., pernah ada istilah al-'azl untuk mencegah kehamilan,pengertian al'ąl dari sudut etimologi (bahasa) adalah at- tanhiyyah (penyingkiran atau penjauhan). Artinya menyingkirkan zakar lelaki di luar vagina sebelum tertumpahnya cairan sperma. ${ }^{15}$ Seorang lelaki datang menjumpai Rasulullah saw, dia berkata:

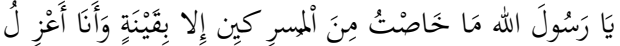

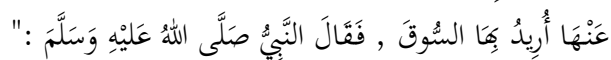

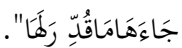

Artinya:

"ya Rasulullah, saat

menyelamatkan diri dari kaum

musyrikin, saya hanya bisa membawa

seorang hamba sahaya wanita dan saya melakukan al'ąl (dalamberhubungan dengannya). Namun, saya akan menjualnya." Beliau bersabda, "Akan ada pada wanita itu, apa yang telah ditentukan untuknya."16

\section{Mengenai Hukum Azl}

Boleh secara mutlak (tanpa syarat), baik diizinkan oleh istri maupun tidak. Akan tetapi, jika seseorang meninggalkannya, maka itu lebih baik. Inilah pendapat yang rojih (pendapat lebih kuat) menurut Syafi'iyah. Alasannya, karena hak istri adalah disenangkan

${ }^{14}$ Majma' Al-Figh, h. 748.

${ }^{15}$ Thariq at-thawari, KB Cara Islam (Cet I; Solo: Maktabah Shaidul Fawa'id alIslamiyyah, 2007), h. 19.

${ }^{16} \mathrm{HR}$ Ibnu Abi Syaibah di dalam Almushannaf (166), Ath-Thabrani di dalam Al- (dengan melakukan 'ål pun sudah terpenuhi), walau tidak keluar mani. Namun untuk melakukan 'azl suami disunnahkan meminta izin pada istri terlebih dahulu.

Membolehkan dengan bersyarat (ada hajat). Jika tidak terdapat hajat, maka 'azl ini dimakruhkan. Inilah yang menjadi pendapat 'Umar, 'Ali, Ibnu 'Umar, Ibnu Mas'ud, dan Imam Malik. Pendapat ini menjadi pendapat kedua di kalangan Syafi'iyah. Pendapat ini juga menjadi pendapat ulama Hanafiyah. Di lain hal, pendapat ini membolehkan 'ąl tanpa izin istri jika zaman telah rusak dan bisa memberikan pengaruh buruk pada anak yang dilahirkan nantinya.

\section{PENUTUP}

Setelah diuraikan pada bab-bab sebelumnya tentang penundaan kehadiran anak akibat perkawinan usia muda (studi pada Desa Jaling Kec. Awangpone Kab. Bone), maka penulis dapat menyimpulkan:

a) Penundaan Kehadiran Anak Akibat Perkawinan Usiamuda Di Desa Jaling Kec. Awangpone Kab. Bone

Akibat dari perkawinan usia muda mereka melakukan penundaan kehadiran anak atau penundaan kehamilan terleibh dahulu, Ini dibuktikan melalui wawancara penulis dengan para narasumber. Selain itu, dalam penundaan kelahiran anak mereka mengikuti Keluarga Berencan (KB) dengan menggunakan suntikan 1 bulan. Alasannya, suntikan 1 bulan lebih aman digunakan untuk pasangan yang baru menikah terutama pada usia

Kabir (2370), Abu Nuaim di dalam Al-Hilyah (IV/362), dan Ibnu Abi Ashim di dalam AsSunnah(663) . Diriwayatkan dari Mandal bin Abi, dari ja'far bin Abu mughirah, dari Abdullah bin Abu Hudzail, dari Jarir. Mandil bin Ali adalah dha'if, dan terkadang dia tsiqah, seperti yang dikatakan oleh Al-Haitsami di dalam Al-Majma'. 
muda dan alasan mereka menunda kehamilan terlebih dahulu berbagai alasan baik itu faktor usia mereka masih muda maupun faktor mereka masih bersekolah sehingga menunda kehadiran anak.

b) Pandangan hukum Islam Terhadap Penundaan Kehadiran Anak Akibat Perkawinan usia Muda

Dapat disimpulkan bahwa metode apapun yang digunakan untuk penundaan kehadiran anak atau penundaan kehamilan boleh-boleh saja dilakukan asalkan adanya persetujuan dari pasangan tersebut, bersifat sementara waktu, serta tidak membahayakan bagi kesehatan yang dapat mendatangkan mudarat dan masalah

\section{DAFTAR PUSTAKA}

Anatang. Yang melakukan Perkawinan usia muda dan Penundan Kehadiran anak. "Wawancara", Jaling, 04 Oktober 2016

Aisyah, siti Yang melakukan Perkawinan usia muda dan Penundan Kehadiran anak. "Wawancara", Jaling, 04 Oktober 2016

Ali Hasan, M. Masail Fiqbiyah alhaditsah:Masalah-masalah

Kontemporer Hukum Islam. Cet. III; Jakarta: PT Raja Grafindo Persada, 1998

Bakar, Zainal Abidin Abu. Kumpulan Peraturan Perundang-undangan dalam Lingkungan Peradilan AgamaCet. II; Jakarta: Yayasan al-Hikmah, 1993

Bambang, Prasetyo dan Lina Miftahul Jannah. Metode Penelitian Kuantitatif Teori dan Aplikasi. Jakarta: Raja Grafindo Persada, 2005

Dahliah. Bidan Desa Jaling. “ Wawancara", Jaling, 04 Oktober 2016
Departemen Pendidikan Nasional. Kamus Besar Bahasa Indonesia. Ed. III; Jakarta: Balai Pustaka, 2002

Departemen Agama. Republik Indonesia, Al-quran dan terjemahnya (Depok: Cahaya Quran, 2011

Departemen Agama RI. Ilmu Fiqh Jilid II. Cet. II; Jakarta: Proyek Pembinaan Perguruan Tinggi/IAIN, 1983

Dokumentasi. Kantor Desa Jaling kecamatan Awangpone kabupaten Bone. Tanggal 04 Oktober, 2016

Eoh, O.S. Perkawinan Antar Agama Dalam Teori Dan Praktek. Cet. I; Jakarta: PT. Raja Grafindo Persada, 2001

Hadi, Sutrisno. Metodologi Research. Cet. XXIII; Yogyakarta: Andi Offset, 1991

Ghazali, Abd.Rahman. M.A.,Fighmunakahat. Cet.L.Bogor:kencana, 2003

Husen, Muhammad,. Fiqih Perempuan Refleksi Kiai atas Wacana Agama Dana Gender. Yogyakarta: LKIS, 2001 